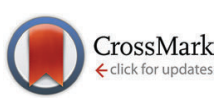

Cite this: Phys. Chem. Chem. Phys., 2017, 19, 1686

DOI: $10.1039 /$ c6cp90299e

www.rsc.org/pccp

\section{Correction: Molecular and ionic diffusion in aqueous - deep eutectic solvent mixtures: probing inter-molecular interactions using PFG NMR}

\author{
Carmine D'Agostino, ${ }^{\star a}$ Lynn F. Gladden, ${ }^{a}$ Mick D. Mantle, ${ }^{a}$ Andrew P. Abbott, ${ }^{\text {b }}$ \\ Essa I. Ahmed, ${ }^{\mathrm{b}}$ Azhar Y. M. Al-Murshedi ${ }^{\mathrm{b}}$ and Robert C. Harris ${ }^{\mathrm{b}}$
}

Correction for 'Molecular and ionic diffusion in aqueous - deep eutectic solvent mixtures: probing inter-molecular interactions using PFG NMR' by Carmine D'Agostino et al., Phys. Chem. Chem. Phys., 2015, 17, 15297-15304.

On page 15303, left column, line 4, the text “...aqueous Ethaline and Glyceline.” should be correctly written as “...aqueous Ethaline and Reline."

The Royal Society of Chemistry apologises for these errors and any consequent inconvenience to authors and readers.

\footnotetext{
${ }^{a}$ Department of Chemical Engineering and Biotechnology, University of Cambridge, Pembroke Street, Cambridge CB2 3RA, UK. E-mail: cd419@hermes.cam.ac.uk

${ }^{b}$ Department of Chemistry, University of Leicester, Leicester LE1 7RH, UK. E-mail: apa1@le.ac.uk
} 